\title{
Laboreal
}

Volume $17 \mathrm{~N}^{\circ} 1$ | 2021

Trabalhar hoje: mudanças, permanências, estratégias, reinvenções

\section{Ergologia e Broadcasting: análise do trabalho de manutenção e suporte em televisão}

Ergología y Radiodifusión: análisis del trabajo de mantenimiento y soporte en televisión

Ergologie et Broadcasting: analyse des travaux de maintenance et support à la télévision

Ergology and Broadcasting: analysis of the maintenance and support work on television

Raquel Figueira Lopes Cancado-Andrade e Alexandre de Carvalho Castro

OpenEdition

Edição electrónica

URL: https://journals.openedition.org/laboreal/17768

DOI: 10.4000/laboreal. 17768

ISSN: 1646-5237

Editora

Universidade do Porto

Refêrencia eletrónica

Raquel Fiqueira Lopes Cancado-Andrade e Alexandre de Carvalho Castro, «Ergologia e Broadcasting: análise do trabalho de manutenção e suporte em televisão», Laboreal [Online], Volume 17 Nº1 | 2021 , posto online no dia 18 junho 2021, consultado o 20 junho 2021. URL: http://journals.openedition.org/ laboreal/17768 ; DOI: https://doi.org/10.4000/laboreal.17768

Este documento foi criado de forma automática no dia 20 junho 2021

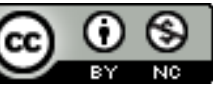

Laboreal está licenciado com uma Licença Creative Commons - Atribuição-NãoComercial 4.0 Internacional. 


\section{Ergologia e Broadcasting: análise do trabalho de manutenção e suporte em televisão}

Ergología y Radiodifusión: análisis del trabajo de mantenimiento y soporte en televisión

Ergologie et Broadcasting: analyse des travaux de maintenance et support à la télévision

Ergology and Broadcasting: analysis of the maintenance and support work on television

Raquel Figueira Lopes Cancado-Andrade e Alexandre de Carvalho Castro

\section{NOTA DO EDITOR}

Manuscrito recebido em: 05/11/2020

Aceite após peritagem em: 17/03/2021

\section{Introdução}

1 Em Broadcasting, o tempo e o trabalho se relativizam pela percepção do cliente final, o telespectador, focada mais em relação àquilo que é transmitido do que ao processo de transmissão. 0 telespectador, enfim, vê o que ocorre na frente da tela. Nesse sentido, porém, há de se destacar toda uma dinâmica de trabalho, com trabalhadores interagindo em atividades para além das telas, antes, durante e até mesmo depois da transmissão e do que eventualmente foi assistido pelo telespectador. $O$ trabalho em Manutenção e Suporte (MeS), para os sistemas que suportam e compõem toda a estrutura em Broadcast, é dos mais complexos e, particularmente, suscita uma interessante reflexão. Daí o objetivo do presente artigo que é analisar a atividade de 
trabalhadores de manutenção, responsáveis pelo suporte à produção e transmissão em Broadcast no Brasil.

2 O Broadcasting - termo que será melhor desenvolvido do ponto de vista histórico-social no tópico seguinte - agrega em si a produção e transmissão de conteúdo jornalístico, educativo e de entretenimento em larga escala. Conteúdo esse, aliás, permanentemente envolto em mudanças, estratégias e reinvenções. Consequentemente, a dinâmica do MeS e a própria estrutura organizacional no setor de Broadcast têm se modificado ao longo do tempo, influenciadas fortemente pela evolução tecnológica.

3 Nos últimos 30 anos, a migração dos sistemas tradicionais de Broadcast de Sistema de TV (como áudio, vídeo, câmeras, matrizes, editores, monitoramento, entre outros) tem ocorrido em direção a um cenário em que se tornam cada vez mais próximos aos Sistemas da Tecnologia da Informação (TI), incorporando elementos tais como o sistema de telecomunicação, a internet, as redes, a segurança de dados e o acesso remoto, entre tantas outras tecnologias. Percebe-se, assim, uma ampla adaptação e reestruturação da infraestrutura, inclusive dos fabricantes, para essa mudança tecnológica e de processo de trabalho. Com isso, o trabalho de MeS também tem se modificado, deixando de ser um trabalho típico de bancada (marcado por troca de peças e concerto de equipamentos), para agregar um viés de atendimento virtual e virtualizado.

4 Essa mudança afeta diretamente como o tempo é vivenciado no trabalho de manutenção e suporte. 0 imediatismo e a necessidade de resolução online têm passado a ser constante, o que marca uma forte ruptura diante do trabalho que era feito anteriormente, mais caracterizado por pesquisa física nos circuitos e placas eletrônicas, testes em conexões, calibração de equipamentos, e troca de equipamentos ou peças por sobressalentes. A manutenção executada de forma manual (do latim manu /"mão"; e tenere /"ter em" ou "segurar") implicava uma demanda de tempo qualitativamente diferente da manutenção que passou a ser mediada em bytes. Os novos ritmos são algoritmos.

5 Houve também uma alteração da forma de se trabalhar no que diz respeito à gestão do conhecimento. Pois a necessidade de implantação de sistemas digitais que atuem em redundância, somada à demanda por pronta resposta, levaram o trabalho de MeS a aumentar ainda mais a sua especificidade. Ou seja, o conhecimento que se busca e desenvolve sobre um determinado sistema resultou, por diversas vezes, numa concentração de expertise em pouquíssimos - quando não únicos - trabalhadores de MeS. Essa alteração também remete a uma nova atividade imposta ao trabalho de MeS, uma vez que o treinamento e a passagem do conhecimento para as áreas operacionais (aquelas que irão manusear o sistema de forma cotidiana) foi agora também agregado ao trabalho de MeS.

6 Todo esse panorama de mudanças implicou a necessidade constante de atuação integrada entre pessoas com trabalhos diferentes. Com a ressalva de que os trabalhadores de manutenção passaram a ter o ônus de garantir que o sistema fosse bem estimado e estruturado, atendendo aos requisitos de projeto, além de bem operado pelos trabalhadores da área de operação. 0 reconhecimento final pelo trabalho bem feito, entretanto, não recai sobre o trabalho de MeS; mas ao contrário, o bônus incide sobre o trabalhador no final da "linha de montagem", ou seja, os trabalhadores de operações ou projetos são os que tendem a ganhar os louros e os elogios pelo padrão de qualidade atingido. 
7 O foco dos tópicos a seguir, portanto, é esse trabalho de MeS em Broadcast, de acordo com a percepção dos próprios trabalhadores da área (os que ainda atuam ou já atuaram nesse tipo de trabalho). Assim, de modo exploratório, através de entrevistas semiestruturadas, buscou-se verificar como os trabalhadores de MeS percebem a dinâmica dessa atividade.

8 A justificativa relacionada ao emprego de tal método, como melhor explicitado a seguir, foi contingencial em decorrência do isolamento social imposto pela pandemia covid-19; e o contexto da pesquisa foi a elaboração de uma dissertação em um Programa de PósGraduação em Engenharia.

\subsection{Histórico do Broadcast no Brasil}

9 Para fins de conceituação, convém caracterizar historicamente o significado de Broadcast, uma vez que o termo radiodifusão, correspondente em português, tende a cair em desuso por conta dos desenvolvimentos tecnológicos. Neste artigo, em um sentido geral, Broadcast pode ser considerado como veiculação de conteúdo educativo, jornalístico ou de entretenimento - feita em mídia de amplo impacto social, como internet, rádio e televisão (Andrade, Castro, Pessanha, Henriques, \& Vinagre, 2019).

10 O Brasil sempre procurou acompanhar a vanguarda tecnológica das comunicações, o que pode ser constatado se forem considerados os anos em que as inovações nessa área foram sendo introduzidas no país, a partir de fins do século XIX (Agência Nacional de Cinema, 2019, 31 março). A primeira exibição de cinema mudo em território nacional, por exemplo, ocorreu apenas um ano após sua invenção pelos Irmãos Lumière no ano de 1895, em Paris, enquanto a primeira exibição de filme sonoro ocorreria somente em 1929. De facto, a partir das primeiras décadas do século XX, o cinema passou a ser considerado como mídia de larga escala, juntamente com o rádio. Assim, a primeira legislação sobre o tema de radiodifusão seria publicada por decreto em 1932 (Decreto $n$. 21.111, 1932).

11 Ao longo dos desenvolvimentos posteriores, contudo, se estabeleceu uma assimetria entre a evolução tecnológica e a pertinência da legislação, situação que perdura até a atualidade, visto que a legislação vigente tem sua base no Decreto n52.795 de 1963 (Lei n. 4.117, 1962; Decreto n. 52.795, 1963). Em 2020, a televisão atingiu o marco de 70 anos de existência no Brasil, mantendo um descompasso de mais de cinco décadas frente às leis reguladoras. Devido a questões políticas, ocorreram integrações e desmembramentos de agências governamentais que tinham algum tipo de interface e poder de decisão sobre o assunto. Detalhar todos esses entraves tomaria muito espaço, bastando salientar que principalmente ao longo do período do regime militar (1964-1985), mas também após o seu término, grupos empresariais de mídia, que mantinham controle e hegemonia nessa área de atuação, eram também apoiadores do governo e não viam com bons olhos mudanças na legislação (Agência Nacional de Cinema, 2019, 31 Março).

12 Mais especificamente a partir da década de 1990, contudo, ocorreram grandes mudanças na estrutura do Broadcasting no Brasil. No ano de 1990, ocorreu a extinção da Embrafilme, do Conselho Nacional de Cinema (CONCINE), e da Fundação do Cinema Brasileiro (FCB). Dois anos mais tarde, aconteceu a criação da Secretaria para o desenvolvimento do audiovisual, que teve uma lei promulgada em 1993. A Agência 
Nacional de Telecomunicações (ANATEL) foi criada em 1997 (ainda que com base em marco regulatório da década de 1970). A Agência Nacional do Cinema (2019) foi criada em 2001, e em 2003 teve início a definição do Sistema Brasileiro de Televisão Digital Terrestre (SBTVD-T). A lei nำ12.485, sobre a TV paga, por sua vez, surgiu em 2011 (Lei $\mathrm{n}$ ำ12.485, 2011).

Figura 1: Interfaces institucionais de Broadcasting no Brasil

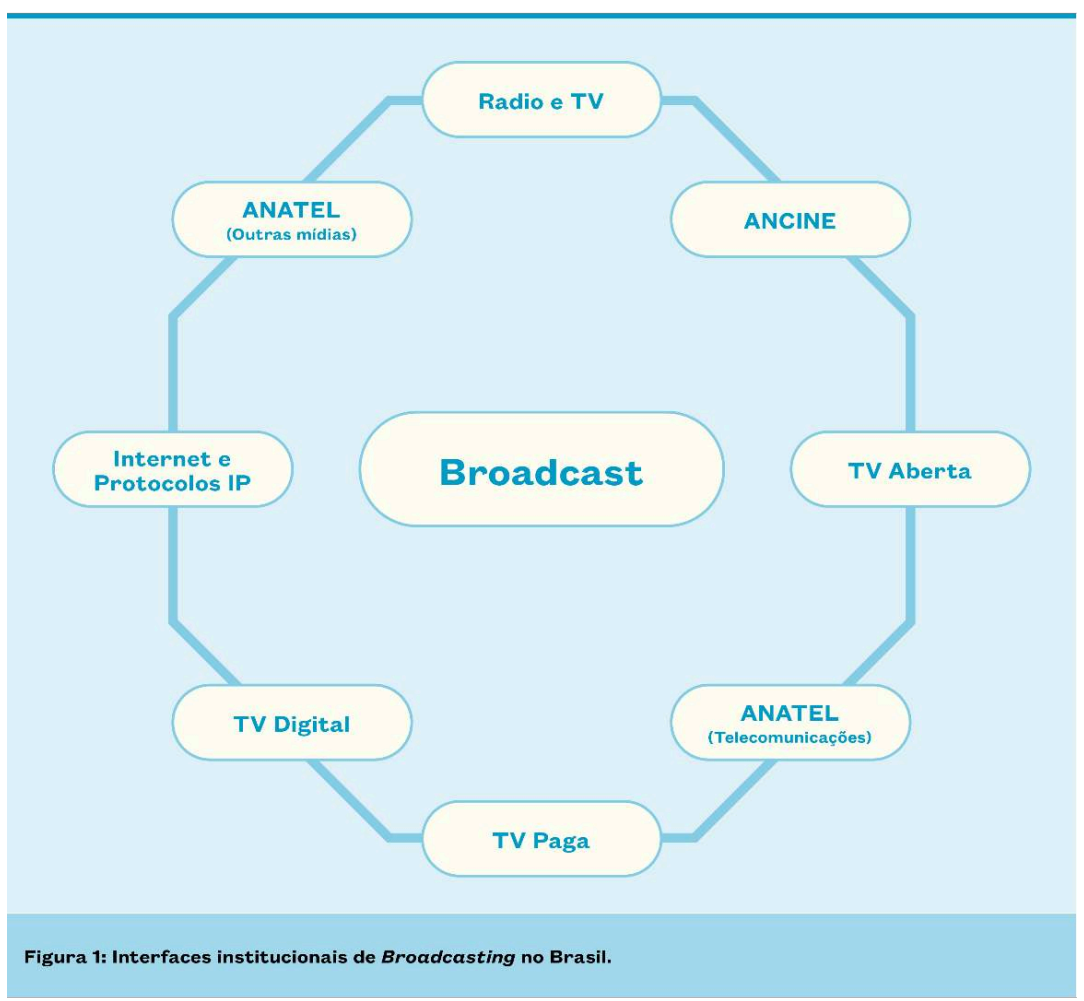

Figura 1: Interfaces institucionais de Broadcasting no Brasil

Diante disso, a Figura 1 procura evidenciar, no âmbito do Broadcasting, algumas das interfaces entre setores de atuação, legislações, área correlatas, mostrando assim, numa síntese, a forma assistemática como a área de Broadcasting tem historicamente evoluído no Brasil.

14 A descrição dessas interfaces é importante, como pano de fundo para a pesquisa, a fim de indicar a ausência de normas governamentais e prescrições legais rígidas nesse campo de atuação. Um dado que resulta em grande flexibilização dos procedimentos de trabalho na área e explica a escassez de regulamentação específica para os setores envolvidos.

\section{Método de pesquisa}

15 A metodologia se pautou por um levantamento prévio em artigos, livros, monografias, leis, decretos, relatórios governamentais e de instituições especializadas. Além disso, foram feitas buscas sistemáticas nas bases de dados da Web of Science, com os descritores "ergologia" e "broadcasting" de forma individual. Devido a ausência de artigos relacionados os temas, ampliou-se a busca acrescentando-se os termos: "radiodifusão", 
"radio difusão", "rádio", "tv", "televisão". Como resultado desse levantamento, se constatou a ausência de investigações abrangendo os temas de ergologia e Broadcast, um dado que torna possível admitir que este artigo contribui para suprir uma lacuna no campo de pesquisa.

16 A próxima etapa da pesquisa foi baseada no recurso de entrevistas semiestruturadas com trabalhadores e ex-trabalhadores de MeS em Broadcasting, principalmente em televisão, embasado pela perspectiva bakhtiniana para a realização das análises dos discursos (Bakhtin, 1929/2004). Isto porque os discursos implicam dialogismos, ou seja, "todos os enunciados no processo de comunicação, independentemente de sua dimensão, são dialógicos" (Fiorin, 2008, p. 19).

Essa vinculação de um quadro teórico orientado às práticas de linguagem e, em especial, à perspectiva bakhtiniana traz à tona a necessidade de definição do conceito de dialogismo, cunhado por Bakhtin (1929/2004). Esse termo é usado para designar um procedimento discursivo que reúne, absorve e reelabora as réplicas de outro discurso, seja um texto escrito ou fala de outrem. Consequentemente, a alusão que um trabalhador faz à fala de seu chefe, ou à fala de um colega, assume importância dialógica, pois o relato da fala do outro se constitui em um discurso relatado, um exemplo claro de dialogismo, porque aponta uma dinâmica de múltiplas inter-relações responsivas no ambiente de trabalho.

Dito em outras palavras, isto aponta a necessidade de um artigo assumidamente bakhtiano analisar o conjunto de vozes diversas, como é feito aqui com os depoimentos dos trabalhadores. Não é o caso, entretanto, de entender o dialogismo de forma reducionista, como uma categoria de análise meramente instrumentalizável (Castro, Portugal, \& Jacó-Vilela, 2011). A visão deve ser mais ampla, a partir da ideia de que o dialogismo favorece um olhar compreensivo e abrangente dos processos de trabalho em Broadcasting, fundamentalmente porque implica conceber a fala dos trabalhadores de MeS como um vasto e complexo universo de interações orientadas sóciohistoricamente.

Em outras palavras, os discursos ou falas são atravessados por ideias gerais, pontos de vista ou interpretação de outros interlocutores. O discurso reflete e refrata a realidade, por isso tais entrevistas são também dialógicas na alternância de perguntas e respostas, iluminando os pontos de vista e valores em jogo (Souza \& Albuquerque, 2012). Desse modo, a partir das técnicas da "Análise do Discurso", buscou-se levantar os atravessamentos do discurso relatado (Rocha \& Deusdará, 2017), mormente em relação a conceitos da Ergologia, como o uso de si por si, e o uso de si por outros, conforme acepção de Schwartz (2013), já que todo trabalho é sempre uso de si, embora possa existir tanto o uso de si por outros (por conta de instruções operacionais variadas), quanto o uso de si por si (por conta de compromissos do trabalhador para consigo mesmo).

Pesquisadores que compartilham tais perspectivas da Ergologia têm avaliado a contribuição bakhtiniana em termos de uma refutação da atitude reducionista pela qual a linguística formalista restringia seu campo de análise (Castro \& Leão, 2020). 0 foco na fala de trabalhadores, via aportes bakhtinianos, portanto, tem sido sobejamente adotado em estudos nessa área. Cenário que solidifica a opção teórico-metodológica adotada neste artigo, e destaca a pluralidade de demandas discursivas na investigação sobre o trabalho de manutenção e suporte (MeS) em Broadcasting. Todos esses sujeitos da pesquisa, trabalhadores formais e assalariados, tinham vínculos com a mesma 
empresa, líder nacional desse segmento de atuação. 0 contato com os trabalhadores de MeS se deu, em princípio, pelas redes sociais WhatsApp e LinkedIn. Optou-se ainda pela utilização do método bola de neve (Vinuto, 2014) - uma forma de amostragem não probabilística que utiliza redes de referência a fim de localizar informantes que indicam seus conhecidos - para se chegar a um maior número de entrevistas.

21 A coleta de dados se deu em etapas. Após o aceite em participar, era requisitado um email do trabalhador para enviar o link da sala virtual onde seria realizada a conversa. Foi criada uma sala virtual na plataforma gratuita "Jitsi Meet" com o nome "Conversa Sobre Trabalho" com senha de acesso. A senha era colocada antes do início das conversas, visto que a pesquisadora incumbida da entrevista entrava na sala virtual com algum tempo de antecedência.

Optou-se por entrevistas individuais, pois devido às constantes mudanças e à imprevisibilidade no setor de Broadcast em televisão, as conversas em grupo se mostraram inviáveis devido a conflitos de agendas. O cenário é de trabalhadores submetidos às demandas inesperadas e alteração repentina de prioridades no trabalho de MeS. Isso porque a escala de trabalho muda com constância e a sua divulgação tende a acontecer sem muita antecedência. Algumas pessoas, inclusive, reportaram um tempo de trabalho, nesse período, de 14 horas contínuas.

Das 17 entrevistas agendadas, sete tiveram uma ou mais remarcações, e várias entrevistas ocorreram aos finais de semana em função da folga dos trabalhadores. 0 termo de consentimento livre e esclarecido foi enviado para o e-mail fornecido pelos entrevistados, juntamente com o link da sala virtual, em dois formatos: um para assinatura e devolução do termo assinado, e outro para leitura no início da conversa. As entrevistas ocorreram entre os dias 27 de julho e 30 de agosto de 2020, no entanto, uma entrevista não pode ser utilizada na análise do discurso, pois o entrevistado não enviou assinado o termo de consentimento livre e esclarecido.

Ao todo, essas entrevistas somaram 793 minutos de gravações. As conversas tiveram duração média de 50 minutos. As transcrições foram feitas por integrantes do grupo de pesquisa [1] e são designadas nos tópicos a seguir pela terminologia abreviada de ENT, com indicação de cada pessoa por seu número correspondente (de 1 a 17). Vale ressaltar que a conversa mais longa teve duração de 82 minutos enquanto a mais curta de 36 minutos.

\section{Resultados e Discussão}

Essa seção foi subdivida a fim de facilitar a abordagem dos resultados encontrados. Assim, cada subtópico apresenta discussões direcionadas a um tema: a técnica da disponibilidade total para a solução imediata, e a disputa entre as equipes de trabalho. Como critério de análise, foram selecionados alguns trechos do corpus das entrevistas, transcritos e citados ao longo do tópico, a fim de referendar os dados das análises. A seleção de tais trechos foi feita com base na relação do enunciado com a atividade específica do trabalhador de MeS, descartando-se as falas de caráter mais geral como, por exemplo, sobre o mercado de trabalho ou a situação econômica do país. 


\subsection{A técnica da disponibilidade total para a solução imediata}

O trabalho em MeS para toda a estrutura em Broadcast é um trabalho técnico e especializado. Do ponto de vista discursivo, aliás, essa atividade é muitas vezes simplesmente referida sob o signo técnica. Tal uso do termo, no entanto, não aponta a necessária formação especializada de dado trabalhador. Não indica especificamente o conhecimento tecnológico implicado em um tipo de especialista. Ao contrário, funciona como um chavão reducionista que não adjetiva uma ação, mas apenas solicita tal ação. De facto, em Broadcast, verifica-se o que pode ser classificado como um gênero discursivo Bakhtiniano, muito evidente no dia a dia do trabalho, quando há repentinos chamados: "técnica!"

Isso ocorre porque há enunciados que, em dada situação social específica, tendem a se estabilizar, ou seja, são repetidos dentro de um contexto que remete aos mesmos sentidos, independentemente do sujeito falante. Tais formas padronizadas de um enunciado, que são relativamente estáveis, recebem de Bakhtin (1952/2003) a denominação de gênero do discurso.

Ora, um enunciado geralmente é repleto de elaborações e ressignificações diversas, mas há contextos sociais tão tipificados, como quando alguém grita "técnica!", que o enunciado tende a ser fixado, reprisado e repetido. Assim, o destaque que merece ser dado é que no ambiente de Broadcast a repetição do mesmo enunciado é decorrente de uma espécie de memória discursiva coletiva (um gênero discursivo) que impulsiona o sujeito falante a reproduzir um mesmo enunciado proferido por outras pessoas em outras interações pregressas.

O Trecho A da entrevista número 11, aludido a seguir, ilustra bem esse tipo de situação:

"Na hora que dá um problema aí o diretor... muitas vezes você estava trabalhando... e o diretor grita: “técnica!”. E você corria lá - “técnica!” - o telefone tocava primeiro, depois era o [chamado no] rádio, hoje acho que é o celular, não é?" (Trecho A)

O fato de ser chamado nesses termos - como técnica - transforma o trabalhador de manutenção e suporte (MeS) em algo impessoal. Sem rosto, sem nome, sem reconhecimento. Sob o estigma de técnica, esse trabalhador passa a ser colocado à inteira disposição de alguém, ou algum setor, mais valorizado. 0 trabalhador de MeS é objeto de uma prática discursiva reducionista, onde pouco importa o quanto de conhecimento e experiência ele tenha, ou quanto ele se dedica a realizar seu trabalho de forma eficiente e eficaz.

31 A perspectiva deste artigo é a de uma discussão ergológica do trabalho, motivo pelo qual convém ressaltar o sentido discursivo de técnica! como uma clivagem evidente entre o uso de si por si, e o uso de si por outros (Schwartz, 2013). Isso porque se o uso de si por si remete a uma atividade alinhada aos sentidos integrais, valores, desejos e afetos do próprio trabalhador; o uso de si por outros indica uma conjuntura produtiva em que o trabalhador se considera como uma ferramenta que atende mais a interesses de outrem.

32 Esse aspeto também é sublinhado porque traz marcas de um discurso relatado (Rocha \& Deusdará, 2017). Em sua fala, o trabalhador relata a fala do diretor. Ele não fala “técnica!" por si, mas fala pelo outro. A situação discursiva é polarizada, entre si e o outro. 
O ponto de maior interesse nessa questão, contudo, é analisar qual capacidade técnica é de fato requerida sob o bojo da interjeição - técnica! o sentido que emerge na análise do discurso desenvolvida a partir das entrevistas mostra que se trata basicamente de uma técnica marcada por dois aspectos principais: a disponibilidade total, e a capacidade de apresentar uma solução imediata.

\subsubsection{A questão da disponibilidade total}

34 A imposição para atendimento de metas e indicadores é uma pressão imposta às equipes de MeS. Essa demanda, no entanto, se faz presente em quase todo trabalho desse tipo em diversas empresas e indústrias. 0 elemento distintivo, em Broadcast, está na imprevisibilidade das rotinas e o fato de que quase sempre há um fluxo praticamente contínuo de produções e transmissões. Nesses casos, os resultados da pesquisa mostraram forte relação discursiva entre "produção de qualquer programa.... uma novela que está sendo gravada" e "a qualquer momento, qualquer situação" (Trecho B da entrevista 1). Consequentemente, em função da ênfase reiterada em qualquer, percebe-se que o trabalho em MeS deve ser realizado sob disponibilidade total.

"É, que a gente atende né, na verdade. Então, por exemplo, produção de qualquer programa.... uma novela que está sendo gravada, os diretores acham que podem falar com a gente de qualquer forma, que a gente tá ali para servi-los a qualquer momento, qualquer situação, e que é um absurdo a gente não conseguir resolver em cinco minutos" (Trecho B)

O fato de o trabalhador estar disponível em qualquer tempo leva o superior hierárquico, o diretor, a poder também falar com este de qualquer forma. A própria utilização da terminologia servi-los parte de uma premissa de hierarquia, subvalorização e subserviência. Ou seja, o trabalhador de manutenção e suporte não é visto como colega de trabalho, ou parceiro, e sim alguém que irá atender a demanda de uma área superior, alguém que serve.

No Trecho $C$ da entrevista 15, a seguir, é possível observar que a questão de estar “100\% do tempo disponível" faz parte de uma dada cultura organizacional, por mais que isso não esteja de fato formalizado de modo objetivo. Essa imposição foi construída historicamente e passada adiante por trabalhadores que "tem 20 anos de casa, 15 anos de casa".

\footnotetext{
- "Mas é aquilo que eu disse: não existe uma obrigação, mas existe uma expectativa velada de que eu esteja $100 \%$ do tempo disponível, porque as pessoas lá mais antigas são de uma cultura em que elas realmente estavam $100 \%$ do tempo disponíveis para a empresa.

- Pesq: Mais antigas, você diz, quem tem quanto tempo?

- Tem 20 anos de casa, 15 anos de casa.

- Pesq: O pessoal mais novo...

- Quem tem mais de dez anos de casa, já é meio que assim.

- Pesq: Está bom.

- O pessoal mais novo tem esse sentimento que eu tenho.

- Pesq: Quem tem menos de dez anos de casa...

- Isso" (Trecho C)
}

Tal necessidade de disponibilidade ao trabalho em sua integralidade, nessa organização produtiva, se enquadra naquilo que a Ergologia chama de normas antecedentes, noção usada para indicar como experiências coletivas produzem normas laborais anônimas 
nas quais ficam subjacentes os valores do grupo (Holz \& Bianco, 2014). Uma norma antecedente, portanto, produz forte pressão por conformidade: "não existe uma obrigação, mas existe uma expectativa velada".

A força da expectativa gerada pelo coletivo de trabalho é percebida como uma obrigação, conforme no Trecho D da entrevista 13: "tem que ser você [...] você está teoricamente num dia de folga [...] se tiver que fazer, faz".

\footnotetext{
"Com certeza e isso eu digo até pela minha experiência, porque eu lembro de situações onde eu estava de volta, nove horas da noite de domingo, estava passeando com a minha esposa e me ligarem: "Fulano [nome do entrevistado Ent13], aconteceu um problema, tem que vir", eu falei: "está bem, mas eu estou de bermuda", "então vai para casa, coloca uma calça e volta para cá porque não pode entrar de bermuda e tem que ser você, tem que vir" e chegar no local e ainda não ter nada. Então, ou seja, você está teoricamente num dia de folga, você perde aquela janela, aquele slot e se tiver que fazer, faz" (Trecho D)
}

39 Há de se ressaltar também que esse tipo de fala mais uma vez apresenta nítidas marcas de discurso relatado (Rocha \& Deusdará, 2017). O trabalhador-enunciador alude ao episódio ocorrido e ainda utiliza e reproduz algumas palavras da direção, como por exemplo "aconteceu um problema, tem que vir (...) tem que ser você, tem que vir". A presença do discurso relatado, nesse caso, evidenciado pela repetição do sintagma tem que vir, visa a construção de uma enunciação tensionada, com pólos distintos. Aspeto, aliás, que deixa de novo claro o uso de de si pelo outro (Schwartz, 2013).

Todos os detalhes aludidos no depoimento - eu lembro - o horário (nove horas da noite), o dia (domingo), o contexto (passeando com a minha esposa), os possíveis impedimentos (mas eu estou de bermuda), e a aparente falta de necessidade de urgência (ainda não ter nada) servem para reforçar a imprevisibilidade e a tensão da possibilidade de ser acionado a qualquer momento. 0 dia de folga é acompanhado pelo termo teoricamente. Ou seja, não é folga, é disponibilidade total.

\subsubsection{A questão da solução imediata}

41 Em muitas organizações produtivas existe uma tendência majoritária focada no desempenho, voltada para alcançar as metas e ter os riscos de operação mitigados. Sendo assim, a busca por soluções imediatas perpassa de um modo geral o horizonte do mundo do trabalho. A situação no caso dos trabalhadores de MeS em Broadcast, contudo, tem particularidades. Isso porque a manutenção deve passar despercebida diante dos telespectadores que podem chegar a um número de dezenas de milhões de pessoas.

Frente a um problema, podem surgir "cenas caóticas". A pessoa que está apresentando um programa televisivo, ou responsável pela produção ou operação do sistema, pode ficar "surtada", "desesperada", "paralisada" e sem conseguir "pensar no que fazer" (conforme o relato da entrevista 1 indicado no Trecho E, a seguir). Em casos como esses, o trabalhador de MeS pode ser acionado a qualquer momento e ter "pouco tempo" para solucionar o defeito, a fim de "não deixar transparecer para o sinal", que está sendo veiculado.

A solução imediata deve ser incorporada ao corpo-si do trabalhador, deve "estar na veia", "tem que estar no sangue para que a pessoa possa reagir rapidamente." 
“É pouco tempo, mas aí que está o caso, você tem que ter o treinamento para saber: quando isso falhou, eu faço aquilo. Então, isso tem que estar na veia, isso tem que estar no sangue para que a pessoa possa reagir rapidamente. Muitas vezes eu assisti cenas caóticas, porque às vezes você tinha que chegar e falar com a pessoa. Ele que comandava a situação, era ele que tinha que atuar. E você tinha que chegar lá e dizer: aperta o botão tal, faz tal coisa, aciona tal máquina, bate tal sistema. Porque a pessoa estava tão surtada, tão desesperada com o que estava acontecendo, que a sensação que dava era que estava paralisada. Não conseguia pensar no que tinha que fazer. Então, você tinha que chegar e indicar os passos para normalizar essa programação. Como eu falei, para não deixar transparecer para o sinal, que estava sendo veiculado, que tinha algum problema. Daí você batia os backups, chama os sistemas redundantes, deixava aquilo no ar e então tratava o problema que estava acontecendo para, assim, investigar o que havia ocorrido". (Trecho E) daquilo que não está. o curto período de um intervalo comercial, único disponível para realização das manobras necessárias - acionar os sistemas redundantes ou backups - é uma contração significativa do tempo da atividade, do prazo geralmente necessário para a manutenção do sistema.

\begin{abstract}
“Então, atendíamos sim sistemas vitais que colocavam o sinal no ar. Quando um desses equipamentos sinalizava problema, era correria geral, às vezes você dispunha de 30 segundos - que era o intervalo de um comercial na época. Quando surgia um problema nesse tipo de sistema, tínhamos 30 segundos, às vezes, para dar conta do problema e colocar tudo ao ar. Claro que existiam sistema de backup, ou backup do backup; ou seja, uma sequência montada para garantir que caso algum falhasse, existissem outras formas de gerenciar o problema, e não deixar transparecer que havia algum problema interno. Mas o estresse e a correria era frequente o tempo todo, porque quando acontecia uma coisa dessa, era o tempo de sair correndo e ver o que estava acontecendo para dar conta do recado. Muitas vezes, tínhamos que auxiliar o pessoal que operacionalizava o sistema, porque as pessoas não tinham, vamos dizer, o preparo psicológico e emocional para lidar com aquela situação de crise, então acabava surtando. Porque, imagina, você tinha a responsabilidade de colocar aquilo no ar, você que está apertando os botões para que aquilo tudo aconteça, de repente o sistema fecha, dá um pane geral, e para tudo, então se aquela pessoa não tiver um posicionamento emocional e psicológico muito embasado para poder saber e equacionar os passos, ela entra em desespero" (Trecho F)
\end{abstract}

A maneira de enfrentar "o estresse e a correria" varia em função da maneira como os trabalhadores de MeS renormalizam suas atividades, uma vez que, para a Ergologia, uma dada atividade, conquanto prescrita de forma aparentemente objetiva, pode ser renormalizada pelos trabalhadores (Vinagre \& Castro, 2017). 

diante de si. Ele tem de lidar com exigências impostas continuamente no ambiente de MeS - a correria - e pode se submeter, em certo grau, às várias prescrições organizacionais e normas antecedentes (procedimentos registrados em manuais, instruções técnicas, regras informais, etc.) que de certo modo configuram o uso de si que os outros queriam que ele fizesse, implicando assim o uso de si pelos outros. Por outro lado, no entanto, pode optar por não aceitar tais normas, e em certo sentido renormalizar essas mesmas normas. Uma escolha como essa, para Schwartz (2013), pode ser visível ou não visível, consciente ou não consciente, mas trará sempre à luz a dimensão política da atividade laboral.

$O$ depoimento colhido na entrevista 15 indica que o MeS responde de forma diferente ao atendimento de um chamado dependendo do seu "momento de vida" (Trecho G). Então, a questão do "tempo dedicado a atender determinada coisa" precisa ser relatado em um formulário, mas isso traz várias implicações, pois a organização produtiva pode "não olhar para o desvio-padrão de um número" e consequentemente "tirar conclusões de que: não, aqui eu posso ter menos gente", ou ainda: "aqui, eu posso botar essa pessoa para fazer outras coisas".

A gestão do tempo em MeS está imbricada em “muitas variáveis envolvidas", mas o trabalhador percebe que "os números dizem muitas coisas, mas você precisa olhar além deles". Se o trabalho for feito rápido demais, por conta da busca pela solução imediata, o gestor pode achar que o setor de MeS está com tempo livre e atribuir a ele uma sobrecarga de novas tarefas, ou reduzir a quantidade de pessoas na equipe. Ao se atender às metas do imediatismo, o eventual sucesso repercute na "locação de mão-deobra", o que pode criar um círculo vicioso que penaliza o trabalhador.

- "Imagina: pessoas respondendo em momentos diferentes, a estímulos diferentes ou estímulos iguais, mas cada uma ali no seu momento de vida, na sua situação. São muitos resultados possíveis. Então, eu acho que o processo é muito importante, mas existem limites no Broadcasting que você precisa respeitar, que você não consegue formularizar, eu acho, você não consegue colocar num...

- Pesq: Num formulário?

- É.

- Pesq: Esses limites, você diz com relação a quê, ao equipamento, à gestão, às pessoas?

- À gestão de pessoas e de mão-de-obra - locação de mão-de-obra, por exemplo. Tempo dedicado a atender determinada coisa.

- (...) instalar uma aplicação específica, são muitas variáveis envolvidas. Então, eu tenho muito medo do que esses números podem revelar também, de tentar extrair conclusões, chegar a conclusões, com esses números, mas eles são muito crus. E aí, se você não olhar para o desvio-padrão de um número como esse, você vai tirar conclusões de que: "não, aqui eu posso ter menos gente", ou: "aqui, eu posso botar essa pessoa para fazer outras coisas, porque ela está...". Só que tem que olhar além do número. Eu sei que é muito difícil, porque é uma quantidade... é uma empresa grande. Mas os números dizem muitas coisas, mas você precisa olhar além deles, eu acho, porque são muitas variáveis que não dá para mapear num sistema. Então, eu acho que o processual tem limite também" (Trecho G)

Esse entendimento de como o trabalhador de MeS se encontra em determinado momento de atendimento - pessoas respondendo em momentos diferentes, a 
estímulos diferentes - pode influenciar a execução da tarefa: "São muitos resultados possíveis". Esses hiatos entre o trabalho prescrito e o trabalho real constituem um dos pressupostos básicos da análise ergológica, por viabilizarem um olhar sobre a singularidade de um determinado trabalho sob a ótica de um trabalhador específico.

51 A tendência perante tal espectro de variabilidades, no entanto, tende a ser a exacerbação da ideia de uma solução mais do que imediata. Em suma, o ideal mesmo é uma solução a ser dada antes de o problema acontecer. $\mathrm{O}$ Trecho $\mathrm{H}$ da entrevista 9 , a seguir, exemplifica tal demanda recorrente: "também tem sempre essa pergunta: por que você não previu o defeito?"

Como já visto na entrevista 01 (Trecho F), alguns problemas e situações podem ser previstos de antemão, o que leva ao preparo de "sistema de backup, ou backup do backup; ou seja, uma sequência montada para garantir (...) formas de gerenciar o problema". A entrevista 9, porém, apresenta o relato de uma situação na qual o setor de MeS precisou se justificar, pois a "equipe de suporte foi questionada", e "toda uma documentação" teve de ser preparada, a partir do "site do fabricante" e enviada "para o chefe".

\footnotetext{
"Agora, uma coisa que assim, normalmente quando a gente perde material, mesmo sendo um problema de equipamento, o suporte precisa se justificar. $\mathrm{Eu}$ acabei não falando esse ponto, mas perante a sua pergunta acho que vale a pena comentar, que: "o que queimou?", "queimou o disco", "mas por que não tinham dois discos?" e aí sempre vêm aquelas perguntas. E (...) eu tive que ir lá, procurar no site do fabricante e pegar uma documentação toda justificando porque só tinha um disco e quais eram os direitos e deveres do [operador], tipo o [operador] tinha que ter o dever de fazer o [back up] do projeto dele, tinha que arquivar o projeto. (...) E tinha toda uma documentação que eu tive que enviar, para o chefe da época e aí eu tive que justificar para poder dizer por que a gente não previu o problema, porque também tem sempre essa pergunta: por que você não previu o defeito? (...) É, na verdade a gente a justificou a nossa parte, não sei te dizer se na chefia da operação eles cobraram isso porque eu não estou lá, eu sei que o meu chefe, vamos dizer assim, a equipe de suporte foi questionada sobre e aí a gente fez a nossa parte, nossa justificativa. Agora eu não sei pelo lado da operação como é que foi, eu não sei te dizer" (Trecho $\mathrm{H}$ )
}

53 Não é absolutamente possível aos trabalhadores de MeS conseguir antecipar todos os problemas, haja vista a quantidade de sistemas e equipamentos que existem, a velocidade da evolução tecnológica e da atualização de produtos, além das falhas humanas provenientes do usuário de operação, como nesse caso de falta de backup que era de responsabilidade da área de operação. Nada disso, no entanto, sensibiliza a pressão exercida por uma transmissão prestes a entrar "no ar".

\subsection{Disputas laborais e discursivas entre as equipes de trabalho}

Um dado analítico importante é que a empresa adota a forma de trabalho e a estrutura conhecida por ITIL (Information Technology Infrastructure Library). Do ponto de vista bakhtiniano, isso tem inflexões discursivas relevantes quanto ao uso dos signos linguísticos: problema e incidente.

Na prática organizacional seguida pela empresa, a palavra problema está diretamente relacionada ao nível de atendimento, ou seja, quando um defeito ou solicitação para o 
trabalho de MeS é realizado inicialmente, este vem sob a nomenclatura de incidente, o que gera um ticket direcionado ao atendimento de MeS de primeiro nível. No entanto, há situações em que o tal incidente ocorre repetidamente (ou não é resolvido por um primeiro atendimento da equipe de trabalhadores generalistas). Assim, o incidente muitas vezes repetido passa a ser designado discursivamente como problema, para o qual é escalado uma equipe mais especializada, ou de segundo nível, como é referido no jargão dos trabalhadores de MeS.

Evidencia-se, dessa forma, uma relação dialógica entre palavras e níveis de especialização e notoriedade no ambiente de trabalho. O termo problema marca hierarquizações, especificações, valores e prestígios. De fato, a divisão de atividades e funções, que existe entre as equipes de atendimento de MeS de primeiro nível (N1, nível 1 ou avançado) e de segundo nível (N2, nível 2 ou especialista), é dialogicamente inferida no que diz respeito à autonomia dos próprios trabalhadores.

Tal discurso configura trabalhadores como dotados, ou não, de autonomia (Dejours, 2012). Assim, os resultados da pesquisa mostram que a equipe de N1 percebe, por vezes, essa autonomia no nível 2; seja pela escala de trabalho, seja por N2 trabalhar com áreas que têm maior reconhecimento. A equipe N2 tem o seu nome atrelado à solução definitiva do problema a ser resolvido. Ainda que, na verdade, a eventual resolução técnica seja precedida por um intenso trabalho do N1.

A fala do trabalhador de N1 descreve que, no fundo, a manutenção inicial cria subsídios para o trabalho do N2: "O nosso trabalho é muito importante, a gente é muito safo, a gente resolve, a gente é muito empenhado e comprometido em resolver as coisas da melhor maneira possível o mais rápido possível, e aí a gente coleta muitas informações, a gente quase faz a entrega final" (veja a seguir Trecho I da entrevista número 15).

\footnotetext{
- "O sentimento da gestão é de que funciona muito bem. (...) o formato anterior, de que eram três grandes grupos especialistas, e essas pessoas se revezavam naquele atendimento de avançado, de primeiro atendimento, com uma escala, sei lá (...) isso funcionava melhor.

- Pesq: As pessoas das equipes, que são hoje...

- Suporte mesmo, isso.

- Pesq: Tanto avançado, quanto especialista? Você acha que elas...

- Isso. E acaba existindo um respeito maior tanto da operação, quanto da gestão nossa, pelos especialistas.

- Pesq: Por quê?

- É como se a gente só estivesse ali - a gente, suporte avançado - para apagar os incêndios. $O$ nosso trabalho é muito importante, a gente é muito safo, a gente resolve, a gente é muito empenhado e comprometido em resolver as coisas da melhor maneira possível o mais rápido possível, e aí a gente coleta muitas informações, a gente quase faz a entrega final, muitas vezes, a entrega final não é nossa por uma questão de um arrematezinho ali, e aí o nome que fica não é o nosso. A gente é muito utilizado para: "preciso de uma ajuda com isso aqui", aí a gente vai lá, coleta aquele monte de informação, faz um monte de verificação inicial, mais para entregar aquilo ali como um material para o especialista trabalhar. Então, eu acho que a gente é meio subutilizado.

- Pesq: Entendi. Ou sub visualizado.

- Sub visualizado.

- Pesq: E super utilizada?

- Super utilizado, é isso aí. Eu disse subutilizado no sentido de que a gente pode muita coisa, e a gente, às vezes, não é solicitado para fazer essas muitas
} 
coisas. Às vezes, a gente é solicitado para fazer coisas para ajudar o especialista a fazer o trabalho dele" (Trecho I)

59 A fala "a gente é meio subutilizado" aponta uma situação de inadequação. O trabalhador do primeiro nível é quem faz plantão, e é quem acaba sendo acionado no corredor para solucionar o incidente que está "no ar". Com isso, o trabalhador que atua como N1, por vezes, não tem tempo para investigar a fundo, ou se debruçar mais detalhadamente para chegar à resolução definitiva, porque a demanda é muito imediata.

60 Por outro lado, emerge o dialogismo bakhtiniano por parte dos funcionários do segundo nível, quando eles aludem à fala presumível de um interlocutor imaginário: “as equipes, o pessoal do suporte do primeiro nível, acha que o segundo é muito melhor, e não é bem assim" (veja a seguir Trecho J da entrevista número 17). Na visão da equipe do N2, o pessoal do N1 não necessariamente precisa direcionar alguns chamados (ou escalar no jargão de MeS), porque a informação (o passo-a-passo de como resolver o problema) já estaria disponível de alguma maneira, como, por exemplo, em um banco de conhecimento acessível a todos os trabalhadores de MeS.

- “É, isso. É porque o suporte, ele é dividido em dois níveis. Então tem o primeiro nível, que é o suporte avançado, e o segundo, que é o que eu pertenço, que eles chamam de suporte especialista, o segundo nível. Então o primeiro nível, ele é 24 horas, e aí sim, lá é 24 horas, 24/7. É bem mais pesado nesse sentido. No nosso caso, e no meu caso, como eu sou do dois, do segundo nível, então é horário comercial mesmo.

- Pesq: Tá. E você sente diferença entre essas equipes de avançado e especialista?

- Diferença em que sentido? De carga horária?

- Pesq: Não, das pessoas às vezes quererem ou mudar do avançado para o especialista...

- Sim...

- Pesq: Por conta do horário, ou por conta - enfim, não sei, de carga de trabalho ou alguma coisa assim.

- Sim, sim. Existe muito, acho que por mais que o trabalho de dois níveis são escopos diferentes, o primeiro nível ele é mais focado em primeiro atendimento na atuação de incidentes e o segundo, de atuação em cima de problemas e de projetos, eu acho que o fato de você estar sempre relacionado muito a projetos ali, isso acaba dando a impressão para as equipes de primeiro nível que o segundo é melhor. Então existe, eu vejo uma vontade muito grande das pessoas, normalmente do primeiro nível quererem ir para o segundo, o suporte especialista.

- Pesq: E você entende que realmente existe essa diferença? Talvez esse olhar diferenciado, até por, não sei, por outras partes da empresa, ou gestores, ou até outras equipes de manutenção, não sei?

- Sim, eu acredito que sim. Eu confesso que até como o primeiro nível, ele lida direto com o cliente - esse é um dos maiores desafios do primeiro nível, na minha opinião. Então eu acho que o trabalho do suporte de primeiro nível, ele tende a ser realmente um pouco pior na minha visão. Mas eu acho que, no geral, as equipes, o pessoal do suporte do primeiro nível, acha que o segundo é muito melhor, e não é bem assim. Eles pensam que só tem vantagem, mas eu acredito que, justamente por ser o segundo, a gente passa a ter mais responsabilidade, enfim, normalmente, como eles escalam problemas para a gente, a gente muitas vezes não tem para quem escalar, a gente tem que resolver. Então é uma apreensão muito grande e tem toda a parte de você ter que ter um conhecimento, ou ter que ter ali a agilidade 
para você buscar a informação rápida. Enfim, eu acho que sim, é um setor que talvez tenha uns pontos realmente positivos em relação ao primeiro nível, mas eu percebo que as pessoas acham que é melhor do que parece. Assim, bem ou mal, eles têm sempre alguém para recorrer, a gente, nem sempre. Eu acho que esse é o ponto" (Trecho J)

61 O próprio termo escalar traz em seu bojo a conotação de se subir de um nível inferior para outro mais alto. Então, ao passo que o N1 almeja posteriormente o crescimento para N2 ("eu vejo uma vontade muito grande das pessoas, normalmente do primeiro nível quererem ir para o segundo"), a fim de pertencer a uma equipe mais especializada; o N2 - justamente essa equipe mais valorizada - se diferencia do nível inferior alegando que falta maior dedicação da equipe de atendimento do $1^{\circ}$ nível.

Do ponto de vista discursivo, a atividade da equipe de N2 é descrita com o termo arrematezinho, argumento complementado com a frase final do Trecho I: “Às vezes, a gente [N1] é solicitado para fazer coisas para ajudar o especialista [N2] a fazer o trabalho dele". Essa disputa discursiva e a tensão entre equipes fica evidente porque o que é arrematezinho se transforma na fala do outro em "mais responsabilidade", porque "a gente muitas vezes não tem para quem escalar, a gente tem que resolver".

63 A alegação de que N1 poderia escalar, mas o próprio N2 não tem essa opção, expressa um sentimento de pressão por resultados: “Então é uma apreensão muito grande e tem toda a parte de você ter que ter um conhecimento [...] bem ou mal, eles [N1] têm sempre alguém para recorrer, a gente [N2], nem sempre. Eu acho que esse é o ponto". É interessante verificar que na fala reportada há um ponto de conflito existente entre os dois níveis. o primeiro nível tem a quem recorrer, como se, no fundo, esse primeiro nível supostamente não precisasse mesmo resolver o problema.

A abordagem ergológica, para além da mera prescrição da atividade, se interessa pelos impasses do labor real, ao considerar que a divisão do trabalho "é sempre instável" (Schwartz, 2011, p. 30). Com essa decomposição do trabalho de MeS em dois níveis, em que se transforma o trabalho? O trabalho se transforma numa divisão que por vezes pode causar constrangimentos aos trabalhadores, disputas internas entre equipes, e falta de clareza, inclusive, dos processos de trabalho. Com isso, ao se tentar dividir e delimitar as exatas atividades a serem executadas (e as responsabilidades e funções), por vezes, gera uma sobreposição de funções, justamente pelo processo não ser entendido e consentido por todos.

A análise das entrevistas permite constatar uma disputa organizacional no interior das atividades de MeS. Isto é, apesar dos trabalhadores se completarem, na perspectiva organizacional normativa da prescrição dos serviços, o crédito final para a resolução é dado ao trabalhador especialista. Por consequência, isso gera um descontentamento por parte dos trabalhadores do primeiro nível, devido à falta de reconhecimento. Embora a perspectiva das normas de manutenção seja a cooperação entre as equipes, o que os resultados da pesquisa indicam é a latente tensão e a contradição implicada no trabalho de MeS dos dois níveis de atendimento.

\section{Considerações finais}

A dinâmica de trabalho no âmbito do Broadcasting é especialmente suscetível às mudanças sociais, impermanências e reinvenções produtivas, devido às contingências 
continuamente inovadoras de produção de conteúdo, na última década, por conta do acesso cada vez maior à internet.

MeS é marcada pela imprevisibilidade, um dado que ressalta a assimetria entre o trabalho prescrito e o trabalho real. Conforme enfatizado na discussão sobre o pano de fundo histórico, o presente objeto de estudo também é circunstanciado pela ausência de normas governamentais e regulamentações legais rígidas nesse campo de Broadcast no Brasil, aspecto que talvez seja uma das causas da grande flexibilização dos procedimentos de trabalho MeS.

As entrevistas trouxeram à tona como a demanda pela disponibilidade total do trabalhador, assim como a busca por soluções imediatas, interferem na forma de trabalho MeS. Do mesmo modo, evidenciou tensões no relacionamento entre membros de uma mesma equipe que atuam em parceria.

O telespectador senta na poltrona de sua casa e liga seu aparelho. Assim, vê programas jornalísticos, educativos ou de entretenimento, sem sequer imaginar as complexas relações de trabalho implicadas no que está assistindo. A análise da atividade de trabalhadores de manutenção, responsáveis pelo suporte à produção e transmissão em Broadcast, no entanto, mostra que por trás da tela há uma prática discursiva eivada de disputas laborais e pressão permanente por resultados imediatos.

\section{BIBLIOGRAFIA}

Agência Nacional de Cinema (2019). Linha do Tempo Audiovisual brasileiro. Disponível em https:// www.ancine.gov.br/pt-br/timeline

Andrade, R., Castro, A., Pessanha, L., Henriques, M., \& Vinagre, R. (2019, outubro). Engenharia de produção, fatores humanos e broadcasting: notas sobre o campo de estudos. Comunicação apresentada no XXXIX Encontro Nacional de Engenharia de Produção, Santos, Brasil.

Bakhtin, M. (2003). Os gêneros do discurso. In M. Bakhtin (Ed.), Estética da criação verbal (pp. 261-306). São Paulo: Martins Fontes. 
Bakhtin, M. (2004). Marxismo e filosofia da linguagem. São Paulo: Hucitec.

Castro, A., \& Leão, L. (2020). A metamorfose e o campo da saúde mental de trabalhadores: uma análise bakthiniana. Ciência \& Saúde Coletiva, 25(9), 3615-3624. https://doi.org/

10.1590/1413-81232020259.28652018

Castro, A., Portugal, F., \& Jacó-Vilela, A. (2011). Proposição bakhtiniana para análise da produção em psicologia. Psicologia em Estudo, 16(1), 91-99. https://doi.org/10.1590/

S1413-73722011000100011

Decreto $\mathrm{n}^{\circ}$ 21.111, de 1ํ. de março de 1932. (1932, 4 março). Aprova o regulamento para a execução dos serviços de radiocomunicação no território nacional. Presidência da República.

Decreto no 52.795 de 31 de outubro de 1963. (1963, 12 novembro). Aprova o Regulamento dos Serviços de Radiodifusão. Presidência da República.

Dejours, C. (2012). Trabalho Vivo: Trabalho e Emancipação. Brasília: Paralelo 15.

Fiorin, J. L. (2008). Introdução ao pensamento de Bakhtin (1). São Paulo: Ática.

Holz, E. B., \& Bianco, M. F. (2014). Ergologia: uma abordagem possível para os estudos organizacionais sobre trabalho. Cadernos EBAPE.BR, 12, 494-512. https://doi.org/

10.1590/1679-39519106

Lei no 4.117, de 27 de agosto de 1962. (1962, 10 outubro). Institui o Código Brasileiro de Telecomunicações. Presidência da República.

Lei nำ12.485, de 12 de setembro de 2011. (2011, 12 setembro). Dispõe sobre a comunicação audiovisual de acesso condicionado; altera a Medida Provisória n².228-1, de 6 de setembro de 2001, e a Leis $n^{\circ}$ s 11.437, de 28 de setembro de 2006, 5.070, de 7 de julho de 1966, 8.977, de 6 de janeiro de 1995, e 9.472, de 16 de julho de 1997; e dá outras providências. Presidência da República.

Rocha, D., \& Deusdará, B. (2017). Dispositivos da Análise Institucional para a explicitação da dimensão política das práticas discursivas. MOARA - Revista Eletrônica do Programa de Pós-Graduação em Letras, 1(47), 108-127. http://dx.doi.org/10.18542/moara.v1i47.5281

Schwartz, Y. (2011). Conceituando o trabalho, o visível e o invisível. Trabalho, Educação e Saúde, 9, 19-45. https://doi.org/10.1590/S1981-77462011000400002

Schwartz, Y. (2013). Histórico e conceitos da ergologia, entrevista com Yves Schwartz. Reflexo \& Ação, 21(1), 327-340. https://online.unisc.br/seer/index.php/reflex/article/viewFile/3742/2923 Souza, S. J., \& Albuquerque, E. (2012). A pesquisa em ciências humanas: uma leitura bakhtiniana. Bakhtiniana: Revista de Estudos do Discurso, 7(2), 109-122. https://doi.org/10.1590/ S2176-45732012000200008

Vinagre, R., \& Castro, A. (2017). Análise da atividade de maçariqueiros num estaleiro no Brasil: Considerações sobre saúde do trabalhador numa perspectiva ergológica. Trabajo y Sociedad, 28, 181-193.

Vinuto, J. (2014). A amostragem em bola de neve na pesquisa qualitativa: um debate em aberto. Temáticas, 22(44), 203-220.

\section{RESUMOS}

O Broadcasting designa, em termos gerais, a produção e transmissão de conteúdo jornalístico, educativo e de entretenimento em meios de comunicação de massa. Nesse cenário, o trabalho em 
Manutenção e Suporte (MeS), para os sistemas que suportam e compõem toda a estrutura em Broadcast, é dos mais complexos, o que suscitou o objetivo de analisar a atividade desses trabalhadores de manutenção, responsáveis pelo suporte à produção e transmissão em Broadcast no Brasil. Fundamentado numa perspectiva ergológica e bakhtiniana, o formato metodológico de entrevistas semiestruturadas permitiu o registro e a análise das falas dos próprios trabalhadores, mediante o uso de uma sala virtual. Os resultados da pesquisa mostraram uma atividade de trabalho eivada de disputas laborais entre equipes e pressão permanente por disponibilidade integral e resultados imediatos.

La radiodifusión se refiere, en términos generales, a la producción y transmisión de contenidos periodísticos, educativos y de entretenimiento en los medios de comunicación social. En este escenario, el trabajo de Mantenimiento y Soporte (MeS) de los sistemas que soportan y componen toda la estructura en emisión, es uno de los más complejos, lo que planteó el objetivo de analizar la actividad de estos trabajadores de mantenimiento, responsables del soporte de la producción y transmisión de radiodifusión en Brasil. Partiendo de una perspectiva ergológica y bakhtiniana, el formato metodológico de entrevistas semiestructuradas permitió la grabación y análisis de los discursos de los propios trabajadores, mediante el uso de una sala virtual. Los resultados de la encuesta mostraron una actividad laboral plagada de disputas laborales entre equipos y una presión permanente por la plena disponibilidad y resultados inmediatos.

Le Broadcasting désigne, en termes généraux, la production et la transmission de contenu journalistique, éducatif et de divertissement, dans des médias de masse. Dans ce scénario, le travail en Maintenance et Support (MeS), pour les systèmes qui supportent et composent l"ensemble de la structure en Broadcast, est des plus complexes - ce qui a suscité le projet d"analyser l"activité de ces agents de maintenance, responsables du support à la production et diffusion en Broadcast au Brésil. Basé sur une perspective ergologique et bakhtinienne, le format méthodologique des entretiens semi-structurés a permis l"enregistrement et l"analyse des verbalisations des travailleurs eux-mêmes, grâce à l"utilisation d"une salle virtuelle. Les résultats de l"enquête ont montré une activité de travail truffée de conflits de travail entre les équipes et une pression permanente pour une disponibilité totale et des résultats immédiats.

Broadcasting refers, in general terms, to the production and transmission of journalistic, educational and entertainment content in mass media. In this scenario, the work in Maintenance and Support (M\&S), for the systems that support and compose the entire structure in broadcast, is one of the most complex, which raised the objective of analyzing the activity of these maintenance workers, responsible for the production support and broadcast transmission in Brazil. Based on an ergological and Bakhtinian perspective, the methodological format of semistructured interviews allowed the recording and analysis of the speeches of the workers themselves, using a virtual room. The survey results showed a work activity riddled with labor disputes between teams and permanent pressure for full availability and immediate results.

\section{ÍNDICE}

Palabras claves: mantenimiento, radiodifusión, ergología, televisión, análisis del discurso

Mots-clés: maintenance, diffusion, ergologie, télévision, analyse du discours

Palavras-chave: manutenção, broadcasting, ergologia, televisão, análise do discurso

Keywords: maintenance, broadcasting, ergology, television, discourse analysis 


\section{AUTORES}

\section{RAQUEL FIGUEIRA LOPES CANCADO-ANDRADE}

https://orcid.org/0000-0001-7122-5053

Programa de Pós-Graduação de Engenharia de Produção e Sistemas do Centro Federal de Educação Tecnológica Celso Suckow da Fonseca - CEFET/RJ, Rua Fábio Luz, 135 - Bloco 2, apto 702 - Méier, Rio de Janeiro/RJ, CEP: 20720-350

raquel.cancado.andrade@gmail.com

\section{ALEXANDRE DE CARVALHO CASTRO}

https://orcid.org/0000-0002-8140-3738

Programa de Pós-Graduação de Engenharia de Produção e Sistemas do Centro Federal de Educação Tecnológica Celso Suckow da Fonseca - CEFET/RJ, Rua General Canabarro, 485 - Bloco E, 5o Andar - Maracanã, Rio de Janeiro - RJ, CEP: 20271-204

o.aken@uol.com.br 